\title{
IMPLEMENTASI FRAMEWORK BOOTSTRAP PADA SISTEM KERJA PRAKTEK BERBASIS WEB RESPONSIVE
}

\author{
Hafiz Maulana Siagian , M. Irwan Padli Nasution , Triase ${ }^{3}$ \\ 1,2,3 Jurusan Sistem Informasi Fakultas Sains dan Teknologi UIN Sumatera Utara \\ Jl. IAIN No.1, Gaharu, Kec. Medan Tim., Kota Medan, Sumatera Utara 20235 \\ ${ }^{1}$ hafiz.maulana@uinsu.ac.id \\ 2irwannst@uinsu.ac.id \\ ${ }^{3}$ triase@ uinsu.ac.id
}

\begin{abstract}
Abstrak
Sistem informasi memfasilitasi integrasi data, kecepatan dan perkiraan pemrosesan data, meningkatkan kualitas informasi dan kontrol manajemen, meningkatkan layanan, dan menyederhanakan prosedur. Universitas Islam Negeri Sumatera Utara (UINSU) adalah sebuah universitas di Medan, Sumatera Utara, Indonesia. Sains dan Teknologi merupakan salah satu fakultas. Kerja Praktek (KP) merupakan salah satu mata kuliah di program studi sistem informasi yang mewajibkan mahasiswa untuk melakukan KP di perusahaan atau instansi dengan persyaratan saat ini. Sistem ini dapat memberikan laporan kerja praktek, petunjuk kerja praktek, izin kerja praktek, dan informasi kerja praktek. Tujuan dari penelitian ini adalah untuk mengumpulkan data tentang KP, mempermudah pengolahan data, dan membuat sistem informasi kerja (KP) yang realistis di Universitas Islam Negeri Sumatera Utara Fakultas Sains dan Teknologi Medan. RAD (Rapid Application Development), bahasa pemrograman PHP, dan database MySQL semuanya digunakan dalam proses pengembangan sistem. Sistem dapat menyajikan informasi kerja praktek berbasis web yang responsif yang dapat memudahkan kegiatan KP di FST seperti bisa mendapatkan izin KP secara online, melaporkan kegiatan KP setiap hari dengan tepat waktu, dan mengunggah hasil laporan KP. hasil akhir yang dievaluasi menggunakan black box pengujian.
\end{abstract}

Kata kunci: Fakultas Sains dan Teknologi, Framework Bootstrap, Kerja Praktek, Web Responsive

\section{PENDAhuluan}

Sistem informasi mempermudah integrasi data, mempercepat pemrosesan data, meningkatkan kualitas informasi dan pengendalian manajemen, meningkatkan layanan, dan menyederhanakan prosedur. Sistem informasi adalah kumpulan komponen yang saling berhubungan atau terhubung di dalam perusahaan yang memperoleh, memproses, menyimpan, dan mentransfer data untuk membantu pemenuhan tugas dan pengambilan keputusan [1].

UINSU (Universitas Islam Sumatera Utara) adalah sebuah lembaga pendidikan tinggi di Kota Medan yang memiliki banyak fakultas, termasuk Fakultas Sains dan Teknologi (FST). Ilmu Komputer, Sistem Informasi, Matematika, Biologi, dan Fisika adalah lima program studi yang ditawarkan FST. Ada mata kuliah Kerja Praktek (KP) di prodi sistem informasi, dan topik KP mengharuskan mahasiswa melakukan KP di suatu perusahaan atau instansi dengan persyaratan saat ini [2]. Prosedur pelaksanaan KP saat ini dimulai dengan mahasiswa mengajukan surat KP yang telah disahkan oleh Program Studi, setelah itu pihak administrasi memberikan izin KP pada perusahaan yang ditekuni mahasiswa tersebut. Prodi Sistem Informasi menunjuk Pembimbing KP, setelah itu mahasiswa menyampaikan hasil KP kepada Pembimbing KP, Pembimbing
Akademik, Prodi Sistem Informasi, Perpustakaan, dan Perusahaan. Saat ini implementasi KP di Prodi Sistem Informasi belum terintegrasi secara efektif. Baik tata cara pendaftaran KP maupun pelaksanaan KP, serta pengajuan laporan akhir. Kesulitan lain bagi FST, seperti pemilihan/penugasan pengawas KP dan pemantauan proses KP secara manual, dapat diatasi dengan mengumumkan informasi tentang KP melalui Sistem Informasi KP berbasis website.

Lalu ada penyimpanan data KP yang belum dimasukkan ke dalam database sistem. Misalnya laporan KP mahasiswa yang belum didigitalisasi. Laporan KP Mahasiswa Sistem Informasi UIN Sumut untuk ganjil tahun 2015 berjumlah 55 laporan KP, sedangkan periode ganjil tahun 2016 berjumlah 78 laporan KP, karena jumlah mahasiswa yang melaksanakan KP akan terus meningkat setiap periodenya. Data dapat hilang atau musnah apabila data disimpan secara manual, oleh karena itu diperlukan suatu sistem yang menggabungkan semua data laporan KP sehingga semua prosedur pelaksanaan KP ditangani oleh satu sistem.

Selanjutnya, mahasiswa mencari informasi KP tentang Prodi Sistem Informasi yang masih diturunkan dari mulut ke mulut dan pertanyaan serta tanggapan dari pengalaman mahasiswa yang lebih tua. Kendala dalam penyebaran informasi ini bagi 
mahasiswa yang belum mengenal KP dan kebutuhannya, serta kurangnya waktu untuk mendapatkan informasi yang benar dan terkini. Lalu ada administrasi administrasi, yang berbentuk cetakan dari awal sampai akhir, yang mungkin memakan biaya dan waktu. Mahasiswa kemudian berinteraksi langsung dengan dosen di kampus untuk mengedit laporan KP yang artinya mahasiswa bertemu dengan dosen di kampus untuk memperbaiki kesalahan dalam laporannya. Sebaiknya hindari keramaian selama masa pandemi Covid-19, karena saat ini banyak program online yang dapat membantu mahasiswa dalam menyampaikan laporan dengan cepat dan tanpa harus bertemu dengan dosen.

\section{METODOLOGI PENELITIAN}

Berikut ini adalah metodologi penelitin yang digunakan dalam membuat Sistem Kerja Praktek.

\section{a) Observasi}

Observasi adalah strategi atau teknik untuk mengumpulkan informasi atau data yang melibatkan pengamatan sistematis dan catatan dari peristiwa yang dipelajari [3]. Penelitian ini dilakukan di Fakultas Sains dan Teknologi dan Bagian Akademik melakukan peninjauan langsung dan pedataan secara terstruktur terhadap tujuan yang akan diteliti. Sehingga mendaparkan data maupun informasi yang sesuai kemudian dapat ditarik kesimpulan.

b) Wawancara

Wawancara Salah satu prosedur pengumpulan data dalam penelitian adalah wawancara, yang melibatkan dua orang, satu sebagai informan dan yang lainnya sebagai informer. [4].Wawancara atau diskusi dilakukan di prodi Sistem Informasi supaya data yang diperoleh lebih jelas. Penulis menyelidiki fakta, informasi, dan kerangka informasi dari subjek penelitian dalam wawancara ini. Wawancara dilakukan kepada Ketua Prodi Sistem Informasi UIN SU Bapak Samsudin ST, M.Kom, Sekretaris Prodi Sistem Informasi UIN SU Ibu Triase ST, M.Kom serta Bagian Akademik Ibu Fatma.

c) Studi Pustaka

Menurut Hart studi Daftar Pustaka adalah kumpulan jurnal (baik yang diterbitkan maupun yang tidak diterbitkan) tentang topik tertentu yang terdiri dari informasi, pemikiran, fakta, dan bukti yang dibuat dari sudut pandang tertentu atau menyampaikan sudut pandang tertentu tentang suatu masalah, cara meneliti itu, dan penilaian yang efektif.. [5]. Dalam penelitian ini, menggunakan referensi seperti jurnal-jurnal dan berbagai macam buku yang terkait dengan masalah penelitian. Dari proses studi pustaka diharapkan dapat melengkapi informasi yang berguna untuk membantu dalam penyelesaian masalah.

d) Pengembangan Sistem

Rapid Application Development (RAD) yang tergabung dalam pendekatan aditif digunakan sebagai metode pengembangan sistem. Siklus pengembangan yang pendek dan cepat menjadi fokus RAD. Dalam pengembangan sistem, RAD menggunakan teknik verbatim (berulang) di mana model sistem fungsional dikembangkan di awal siklus pengembangan untuk menentukan kebutuhan pengguna.
Terkadang model kerja berfungsi sebagai dasar untuk desain dan eksekusi sistem akhir.

\section{HASIL DAN PEMBAHASAN}

\subsection{Analisis Sistem Berjalan}

Metode pelaksanaan KP saat ini dimulai dengan mahasiswa mengajukan surat KP yang telah disahkan oleh Prodi, dilanjutkan dengan administrasi mengeluarkan izin KP kepada perusahaan yang dibidik mahasiswa, dan Prodi Sistem Informasi menunjuk pembimbing KP. Seleksi/penugasan pengawas KP masih manual, mengakibatkan mahasiswa kurang memahami apa yang mereka lakukan selama kerja praktek di perusahaan yang disasar mahasiswa, kemudian prosedur pembimbingan masih manual yaitu mahasiswa pergi ke dosen pembimbing, semua kendala FST. Mahasiswa kemudian mencari informasi KP tentang Program Studi Sistem Informasi yang masih berdasarkan dari mulut ke mulut dan tanya jawab dari pengalaman mahasiswa sebelumnya. Kurangnya pemahaman mahasiswa tentang KP, cara persyaratan KP, serta kerangka waktu pelaksanaan yang masih keliru dan ketinggalan zaman menjadi kendala dalam penyampaian informasi tersebut. Lalu ada administrasi, yang dilakukan seluruhnya di cetak dari awal sampai akhir, yang mungkin mahal dan memakan waktu.

3.2. Analisis Sistem Usulan

Dengan mendaftar Kerja Praktek, mengupload laporan KP, dan melakukan bimbingan online melalui sistem Kerja Praktek, sistem baru ini akan membantu mahasiswa dalam memenuhi berbagai kriteria untuk memenuhi proses Kerja Praktek yang ada. Mahasiswa juga dapat memperoleh informasi lebih lanjut tentang Kerja Praktek di Fakultas Sains dan Teknologi UIN Sumatera Utara, mulai dari formulir pendaftaran KP, nilai, dan berita terkini lainnya. Selain mahasiswa, sistem Kerja Praktek yang diusulkan akan membantu dosen dalam menjalankan tanggung jawabnya, seperti memberikan informasi yang up to date kepada mahasiswa, memonitoring mahasiswa saat KP, dan mahasiswa dapat melaporkan bimbingan secara online melalui sistem informasi kerja praktek, dan akademisi dapat mempermudah pengiriman surat balasan atau surat pengantar. Perusahaan kemudian dapat memantau tindakan siswa setiap hari dan memberikan nilai kepada siswa selama KP di perusahaan.

\subsection{Perancangan Sistem}

Sistem usulan pada penelitian ini terdiri dari rancangan usecase, class diagram, dan Desain Database. Gambar 2 memperlihatkan usecase yang akan diusulkan. Use Case Diagram berfungsi melakukan tugas-tugas khusus yang menjadi ciri proses bisnis sistem [7]. Pada Use case ada 5 aktor yaitu akademisi, mahasiswa, program studi, fakultas dan institusi. Dalam sistem ini, program studi berfungsi sebagai pengelola sistem untuk entri data, modifikasi data, penghapusan data pengguna, mahasiswa dan fakultas. Mahasiswa dalam sistem ini diminta untuk memasukkan data $\mathrm{KP}$, melakukan data, data jurnal harian, dan menyerahkan data laporan KP yang telah diverifikasi oleh Prodi. Sedangkan tugas dosen adalah memperoleh informasi tentang data mahasiswa untuk keperluan konseling KP, dan data mahasiswa untuk 
konseling. Perusahaan dapat memasukkan nilai, melihat jurnal harian, dan memperbarui data perusahaan.

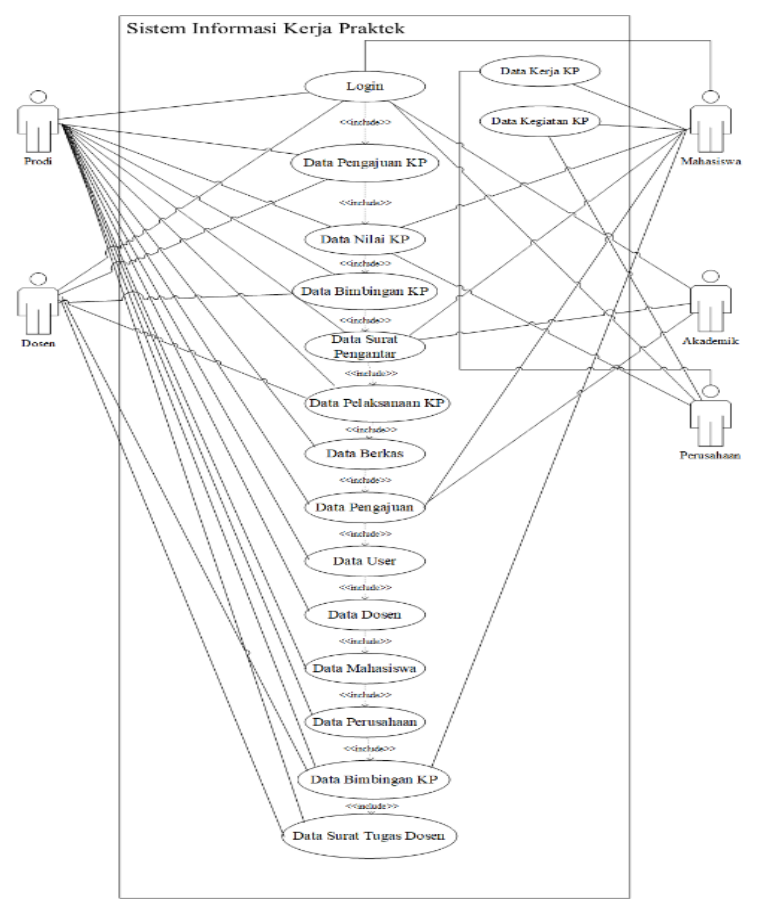

Gambar 1. Usecase Sistem Usulan

Berikutnya adalah class diagram. Class Diagram yaitu model desain sistem, ada hubungan antara kelas dan deskripsi menyeluruh dari setiap kelas. [8]. Gambar 3 merupakan Class Diagram pada penelitian. Class diagram pada penelitian ini terdapat 13 class yaitu, perusahaan, user, bimbingan, surat pengantar, rbac, surat tugas, kegiatan, pengajuan, berkas, jadwal, migration, masterkp, setting.

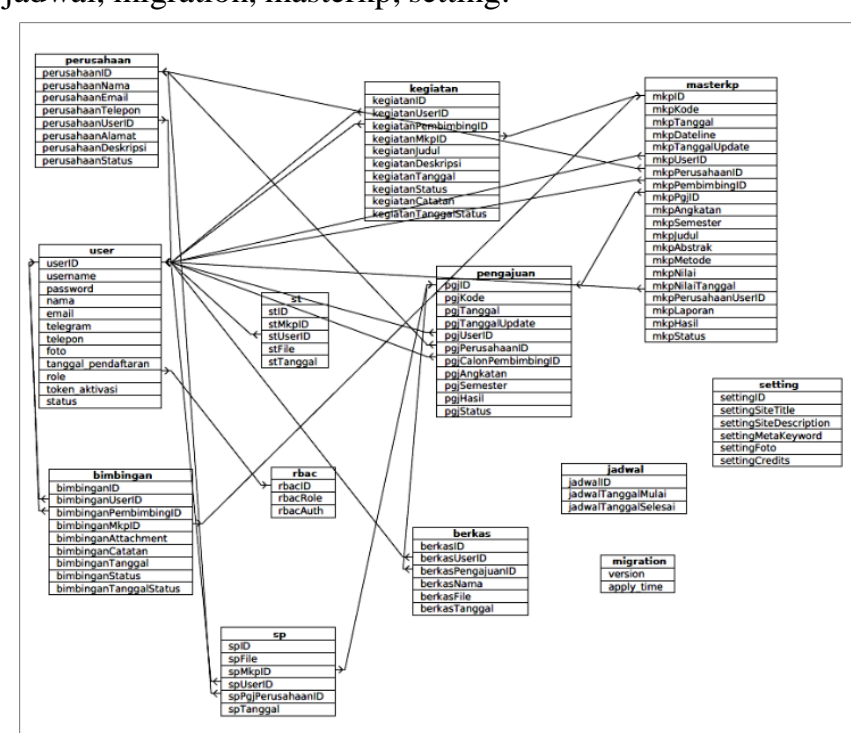

Gambar 2. Class Diagram Sistem Usulan

Adapun selanjutnya adalah tahapan Desain Database. Database adalah kumpulan informasi sistematis yang disimpan

di komputer yang dapat diverifikasi menggunakan aplikasi komputer untuk mengekstrak informasi dari database. [9]. Berikut adalah desain Database pada sistem usulan, terdiri dari 10 yang digunakan dalam pembuatan database untuk sistem ini yaitu tabel master KP, tabel berkas, tabel bimbingan, tabel jadwal, tabel kegiatan, tabel pengajuan, tabel perusahaan, tabel surat pengajuan, tabel surat tugas, dan tabel user antara lain :

Tabel 1. Master KP

\begin{tabular}{|l|l|}
\hline Column & Type \\
\hline mkpID (Primary) & int(11) \\
\hline mkpKode & varchar(200) \\
\hline mkpTanggal & datetime \\
\hline mkpDateline & datetime \\
\hline mkpTanggalUpdate & datetime \\
\hline mkpUserID & bigint(20) \\
\hline mkpPerusahaanID & int(11) \\
\hline mkpPembimbingID & bigint(20) \\
\hline mkpPgjID & int(11) \\
\hline mkpAngkatan & int(4) \\
\hline mkpSemester & varchar(20) \\
\hline mkpJudul & varchar(200) \\
\hline mkpAbstrak & text \\
\hline mkpMetode & text \\
\hline mkpNilai & int(11) \\
\hline mkpNilaiTanggal & datetime \\
\hline mkpPerusahaanUserID & bigint(20) \\
\hline mkpLaporan & varchar(200) \\
\hline mkpHasil & enum('Lulus', 'Tidak \\
& $\begin{array}{l}\text { Lulus', } \\
\text { Selesai') }\end{array}$ \\
\hline mkpStatus & enum('Belum Selesai', \\
& 'Selesai') \\
\hline
\end{tabular}

Tabel 2. Berkas

\begin{tabular}{|l|l|}
\hline Column & Type \\
\hline berkasID (Primary) & $\operatorname{int}(11)$ \\
\hline berkasUserID & bigint(20) \\
\hline berkasPengajuanID & $\operatorname{int}(11)$ \\
\hline berkasNama & varchar(200) \\
\hline berkasFile & varchar(200) \\
\hline berkasTanggal & datetime \\
\hline
\end{tabular}

Tabel 3. Bimbingan

\begin{tabular}{|l|l|}
\hline Column & Type \\
\hline bimbinganID (Primary) & int(11) \\
\hline bimbinganUserID & bigint(20) \\
\hline bimbinganPembimbingID & bigint(20) \\
\hline bimbinganMkpID & int(11) \\
\hline bimbinganAttachment & text \\
\hline bimbinganCatatan & text \\
\hline bimbinganTanggal & datetime \\
\hline bimbinganStatus & $\begin{array}{l}\text { enum('Diajukan', 'Diterima', } \\
\text { 'Ditolak') }\end{array}$ \\
\hline bimbinganTanggalStatus & datetime \\
\hline
\end{tabular}


Tabel 4. Jadwal

\begin{tabular}{|l|l|}
\hline Column & Type \\
\hline jadwalID (Primary) & int(11) \\
\hline jadwalTanggalMulai & datetime \\
\hline jadwalTanggalSelesai & datetime \\
\hline
\end{tabular}

Tabel 5. Kegiatan

\begin{tabular}{|l|l|}
\hline \multicolumn{1}{|c|}{ Column } & \multicolumn{1}{c|}{ Type } \\
\hline kegiatanID (Primary) & int(11) \\
\hline kegiatanUserID & bigint(20) \\
\hline kegiatanPembimbingID & bigint(20) \\
\hline kegiatanMkpID & int(11) \\
\hline kegiatanJudul & text \\
\hline kegiatanDeskripsi & text \\
\hline kegiatanTanggal & datetime \\
\hline kegiatanStatus & enum('Dilaporkan', \\
& 'Terverifikasi', 'Tidak \\
& Terverifikasi') \\
\hline kegiatanCatatan & text \\
\hline kegiatanTanggalStatus & datetime \\
\hline
\end{tabular}

Tabel 6. Pengajuan

\begin{tabular}{|l|l|}
\hline \multicolumn{1}{|c|}{ Column } & \multicolumn{1}{c|}{ Type } \\
\hline pgjID (Primary) & int(11) \\
\hline pgjKode & varchar(200) \\
\hline pgjTanggal & datetime \\
\hline pgjTanggalUpdate & datetime \\
\hline pgjUserID & bigint(20) \\
\hline pgjPerusahaanID & int(11) \\
\hline pgjCalonPembimbingID & bigint(20) \\
\hline pgjAngkatan & int(4) \\
\hline pgjSemester & varchar(20) \\
\hline pgjHasil & $\begin{array}{l}\text { enum('Pengajuan KP Diterima', } \\
\text { 'Pengajuan KP Ditolak') }\end{array}$ \\
\hline pgjStatus & $\begin{array}{l}\text { enum('Menunggu Validasi', } \\
\text { 'Selesai Validasi') }\end{array}$ \\
\hline
\end{tabular}

Tabel 7. Perusahaan

\begin{tabular}{|l|l|}
\hline \multicolumn{1}{|c|}{ Column } & \multicolumn{1}{c|}{ Type } \\
\hline perusahaanID (Primary) & int(11) \\
\hline perusahaanNama & varchar(200) \\
\hline perusahaanEmail & varchar(200) \\
\hline perusahaanTelepon & varchar(20) \\
\hline perusahaanUserID & bigint(20) \\
\hline perusahaanAlamat & text \\
\hline perusahaanDeskripsi & text \\
\hline perusahaanStatus & enum('Aktif', 'Non Aktif') \\
\hline
\end{tabular}

Tabel 8. Pengajuan

\begin{tabular}{|c|c|}
\hline Column & Type \\
\hline spID (Primary) & $\operatorname{int}(11)$ \\
\hline spFile & varchar(200) \\
\hline spMkpID & $\operatorname{int}(11)$ \\
\hline spUserID & bigint(20) \\
\hline spPgjPerusahaanID & $\operatorname{int}(11)$ \\
\hline spTanggal & datetime \\
\hline
\end{tabular}

Tabel 9. Surat Tugas

\begin{tabular}{|l|l|}
\hline \multicolumn{1}{|c|}{ Column } & \multicolumn{1}{c|}{ Type } \\
\hline stID (Primary) & $\operatorname{int}(11)$ \\
\hline stMkpID & $\operatorname{int}(11)$ \\
\hline stUserID & bigint(20) \\
\hline stFile & varchar(200) \\
\hline stTanggal & datetime \\
\hline
\end{tabular}

Tabel 10. User

\begin{tabular}{|l|l|}
\hline \multicolumn{1}{|c|}{ Column } & \multicolumn{1}{c|}{ Type } \\
\hline userID (Primary) & bigint(20) \\
\hline username & varchar(255) \\
\hline password & varchar(255) \\
\hline nama & varchar(35) \\
\hline email & varchar(255) \\
\hline telegram & varchar(200) \\
\hline telepon & varchar(20) \\
\hline foto & text \\
\hline tanggal_pendaftaran & date \\
\hline role & int(11) \\
\hline token_aktivasi & text \\
\hline status & $\begin{array}{l}\text { enum('Pending', 'Aktif', 'Non } \\
\text { Aktif') }\end{array}$ \\
\hline
\end{tabular}

\subsection{Implementasi Sistem}

Implementasi dapat didefinisikan sebagai aktivitas yang berhubungan dengan pekerjaan yang melibatkan penggunaan sarana (alat) untuk mencapai tujuan [10]. Pada tahap ini, perancangan sistem yang dibuat menggunakan pemograman PHP dan database menggunakan MySQL dan memakai framework Bootstrap.

Gambar 3 merupakan homepage, yang berfungsi untuk sebagai identitas website.

Gambar 4 merupakan halaman login, yang berfungsi untuk user yang akan menggunakan aplikasi dengan memasukkan username dan password yang ada pada sistem.

Gambar 5 merupakan halaman menu utama pada Admin prodi, yang berisikan menu data perusahaan, data pengajuan, data berkas, data pelaksanaan KP, data surat pengantar, data surat tugas dosen, data bimbingan KP, data kegiatan KP, data Nilai KP.

Gambar 6 merupakan halaman menu utama pada Mahasiswa, yang berisikan menu data pengajuan, data kerja praktek, data surat pengantar, data bimbingan KP, data kegiatan KP.

Gambar 7 merupakan halaman menu utama pada Dosen, yang berisikan menu data pelaksanaan $\mathrm{KP}$, data surat tugas dosen, data bimbingan KP.

Gambar 8merupakan halaman menu utama pada Akademik, yang berisikan menu data pengajuan dan menu data surat pengantar.

Gambar 9 merupakan halaman menu utama pada Perusahaan, yang berisikan menu data kerja praktek dan data kegiatan KP. 


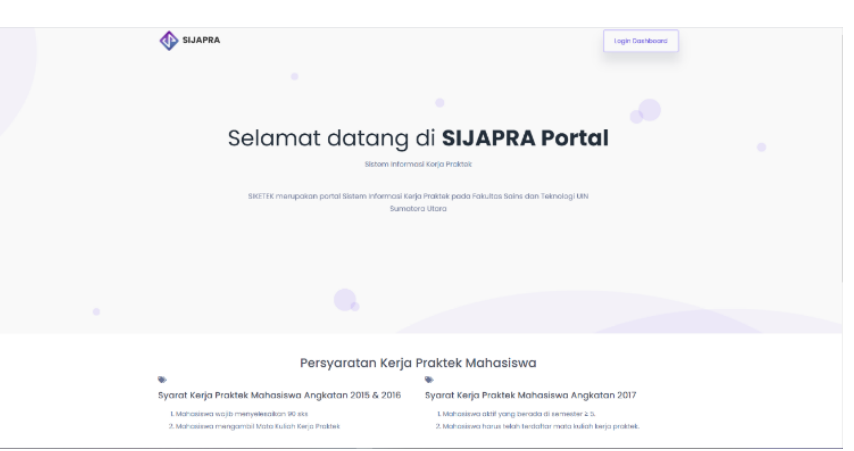

Gambar 3. Home Page

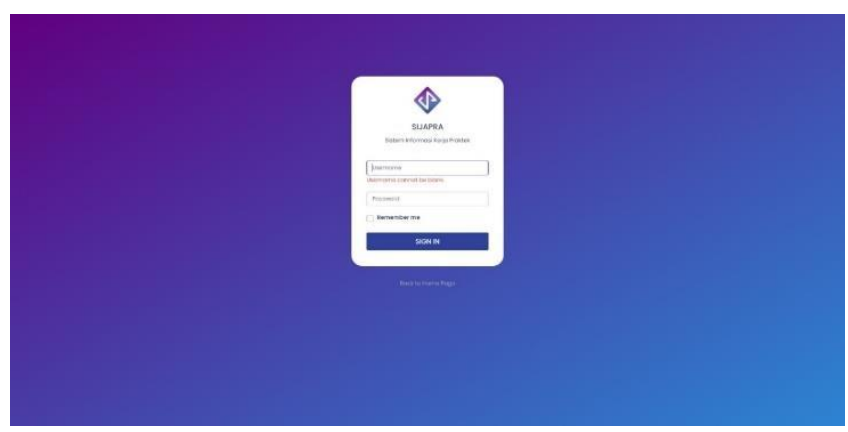

Gambar 4. Login

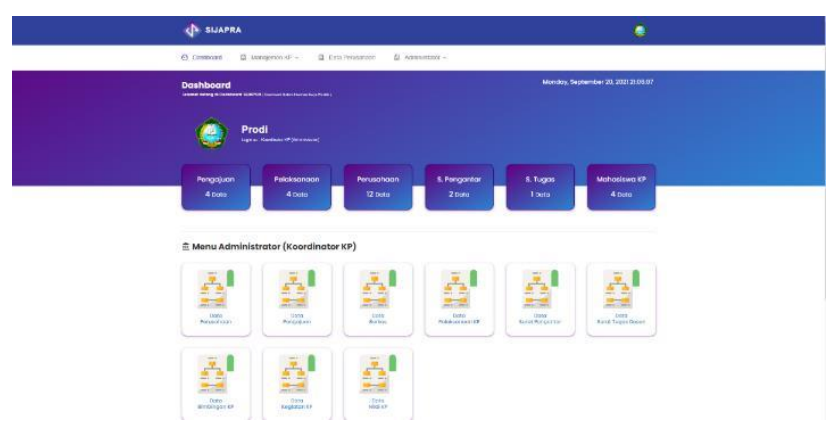

Gambar 5. Menu Utama Admin

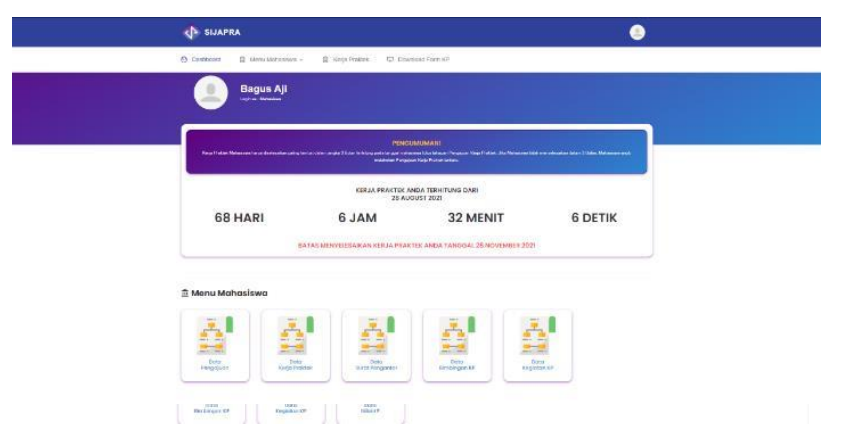

Gambar 6. Menu Utama Mahasiswa

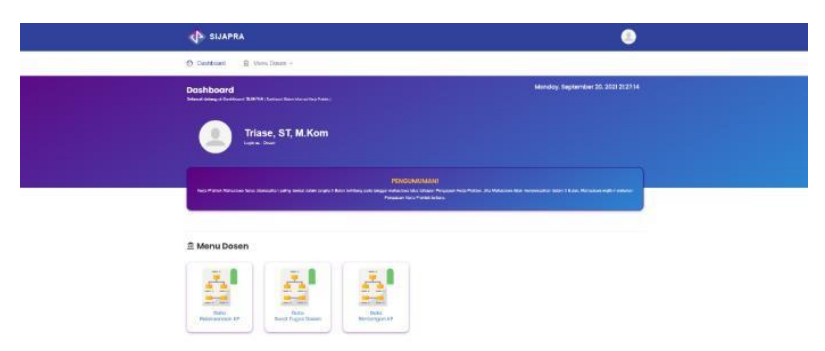

Gambar 7. Menu Utama Dosen

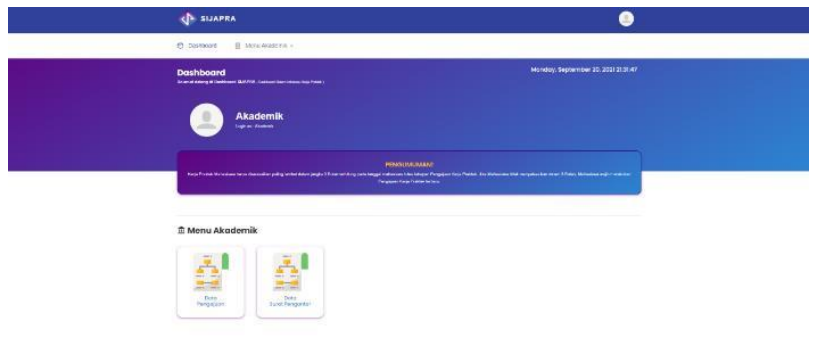

Gambar 8. Menu Utama Akademik

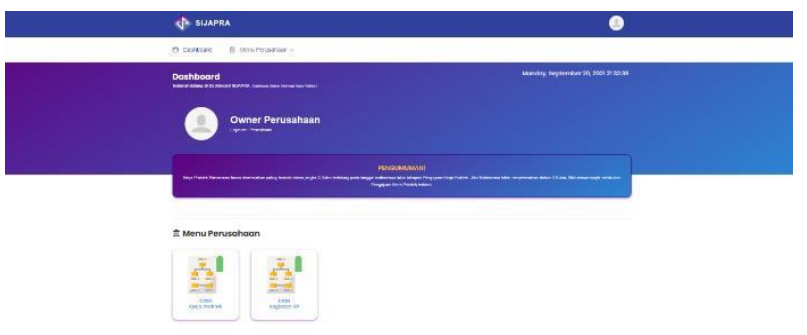

Gambar 9. Menu Utama Perusahaan

\section{KESIMPULAN}

1) Sistem ini menggunakan Framework Bootstrap untuk mempermudah pemakaian dalam Sistem Informasi KP pada Fakultas Sains dan Teknologi UIN SU.

2) Sistem yang telah dibangun, memberikan kemudahan pengolahan semua data KP yang dilaksanakan di Fakultas Sains dan Teknologi UIN SU.

3) Sistem yang dibangun berupa informasi KP yang di dalamnya memuat data-data yang dimulai dari pengajuan KP hingga mengupload laporan KP

\section{REFERENSI}

[1] H. T. Sihotang, "Sistem Informasi Pengagendaan Surat Berbasis Web Pada Pengadilan Tinggi Medan," vol. 3, no. 1, pp. 6-9, 2019, doi: 10.31227/osf.io/bhj5q. 
[2] F. Sains, D. A. N. Teknologi, U. I. Negeri, and S. U. Medan, "Buku panduan penulisan laporan kerja praktik program studi sistem informasi."

[3] R. Widia, V. Novianti, Y. Syahidin, and M. Hidayati, "Sistem Informasi Korespondensi Rekam Medis di Rumah Sakit Menggunakan Microsoft Visual Studio," Expert J. Manaj. Sist. Inf. dan Teknol., vol. 11, no. 1, p. 56, 2021, doi: 10.36448/expert.v11i1.2013.

[4] S. R. I. Solehah, P. Pancasila, D. A. N. Kewarganegaraan, F. Keguruan, D. A. N. Ilmu, and U. M. Mataram, "Skripsi Penanaman Nilai - Nilai Pancasila Dalam Membentuk Karakter Anak Sebagai Upaya Pencegahan ' Lost Generation ' Di Tpa Pendidikan Pesantren $\mathrm{Nu}$ Hidayatul Muttaqin Pagutan," 2019.

[5] L. Aldianto, I. Raafaldini Mirzanti, D. Sushandoyo, and E. Fitriana Dewi, "Pengembangan Science Dan Technopark Dalam Menghadapi Era Industri 4.0 Sebuah Studi Pustaka," J. Manaj. Indones., vol. 18, no. 1, pp. 68-76, 2018, doi: 10.25124/jmi.v18i1.1261.

[6] J. R. Sagala, "Model Rapid Application Development (Rad) Dalam Pengembangan Sistem Informasi Penjadwalan Belajar Mengajar," J. Mantik Penusa, 2018.

[7] Suendri, Triase, and S. Afzalena, "Implementasi Metode Job Order Costing Pada Sistem Informasi Produksi Berbasis Web," J. Sekol., vol. Vol 4, pp. 97106, 2020.

[8] Suendri, "Implementasi Diagram UML (Unified Modelling Language) Pada Perancangan Sistem Informasi Remunerasi Dosen Dengan Database Oracle (Studi Kasus: UIN Sumatera Utara Medan)," J. Ilmu Komput. dan Inform., 2018.

[9] N. Yuslem, M. Nasution, and A. B Syarbaini, "Development of Database of The Abu Lais' Thought Regarding Hadith,” 2020, doi: 10.4108/eai.2-102018.2295289.

[10] A. P. Erwan and R. S. Dyath, "Implementasi_Kebijakan_Publik._pdf.pd f," no. September. p. 194, 2018, [Online]. Available: www.gavamedia.net. 